\title{
Analysis of lung cancer incidence relating to air pollution levels adjusting for cigarette smoking: a case-control study
}

\author{
P. R. Band, H. Jiang \& J. M. Zielinski \\ Population Studies Division, Environmental Health Science and \\ Research Bureau, Environmental and Radiation Health Sciences \\ Directorate, Healthy Environments and Consumer Safety Branch, \\ Health Canada, Ottawa, Canada
}

\begin{abstract}
A case-control study (lung cancer: 2711; age and sex matched non-lung cancer controls: 2711) encompassing the years 1986-2004 was undertaken further to the results of increased mortality and cancer incidence in Windsor, Canada. The objective was to investigate associations between lung cancer incidence and exposure to air pollutants controlling for cigarette smoking and duration of residence. A nominal file of cases and controls ascertained by the Ontario Cancer Registry was obtained from Cancer Care Ontario; smoking information and addresses of residence within Windsor were obtained respectively from medical charts at the Windsor Regional Cancer Centre and from the Windsor City Directories. For each case and control and for each air pollutant, a cumulative exposure was calculated based on duration of residence at each address location; the centroid of postal codes of addresses was used as proxy for residential location. For each location, annual $\mathrm{NO}_{2}$ and $\mathrm{SO}_{2}$ levels were estimated, using Land Use Regression based on results from 54 monitors within Windsor. Results obtained from conditional likelihood regression for matched or stratified data, (including sex, age at diagnosis, numbers of cigarette smoked per day and duration of smoking as covariates) are presented.

Keywords: air pollution, cigarette smoking, lung cancer, case-control study.
\end{abstract}




\section{Introduction}

Long-term exposure to air pollution particles (Dockery et al. [1], Pope et al. [2, 3], Beeson et al. [4]), nitrogen dioxide (Nyberg et al. [5]) and nitrogen oxides (Nafstad et al. [6, 7]) has been associated with an increased lung cancer risk. In January 2003, the Governments of Canada and of the United States launched the Canada-US Border Air Quality Strategy (BAQS) to assess health effects of populations exposed to air pollution in these border regions. The following key objectives were determined: collecting human health data; analyzing evidence of human health impacts and assessing the risk to human health exposed to air pollution. The municipality of Windsor, situated in the most southern part of the Province of Ontario, Canada, was selected as one of BAQS target because of its proximity to the city of Detroit, U.S.A, and because of traffic pollution with about 10,000 trucks crossing the bridge linking Windsor to Detroit each day. In a preliminary study, we reported an increased risk of lung cancer incidence and mortality in males and females residents of Windsor (Band et al. [8]). Results assessing health effects of air pollution exposure have serious limitations inherent to mortality and cancer incidence studies. In particular, information on smoking and duration of residence at specific residential locations is lacking. In this paper, we present preliminary results of a case-control study assessing the relationship between lung cancer and chronic exposure to $\mathrm{SO}_{2}$ and $\mathrm{NO}_{2}$, controlling for cigarette smoking and residential duration.

\section{Feasibility study}

Prior to undertaking the project, a feasibility study was conducted to: a) review a random sample of 30 medical charts to verify if smoking information was reported by staff physicians and/or nurses; b) obtain precise information on medical file location and accessibility; c) obtain precise information on address and residential duration at given addresses in Windsor from public community records.

Thirty randomly selected medical charts from lung cancer cases (20) and from non-lung cancer controls (10) diagnosed prior to 1990 were reviewed. Of the lung cancer cases, the number of cigarettes smoked per day and the years of smoking were available for 18 with one information missing; one case was a non-smoker. Of the controls, five were never smokers, one had no smoking information and in four, intensity and duration of smoking were available. Thus, in total, smoking information was recorded for 27 (90\%). Medical charts were in electronic format at the Windsor Regional Cancer Centre since April 1999. Prior to that date, medical charts of patients no longer seen at the centre were stored out of site at a privately owned Records Management Company in Windsor. A review of the accessibility of data included in the Property Assessment files, Voter's list, Windsor City Land Registry and Windsor City Directories was undertaken. The Windsor City Directories, available since the late 1800 were the only useful and readily available database from which address information over 
time could be accurately obtained. It was thus concluded from the feasibility study that adequate information was available to proceed to the planned casecontrol study.

\section{Method}

\subsection{General}

Population data for the City of Windsor and for enumeration areas within the City of Windsor was obtained from Statistics Canada annually from 1986 to 2004. A nominal file of cases and controls were obtained from the Ontario Cancer Registry, Cancer Care Ontario. All 2,711 lung cancer cases occurring during 1986 to 2004 inclusive among residents of the City of Windsor were included in the study. 2,711 randomly selected cancer controls and residents of the City of Windsor at time of diagnosis during the same time period were matched on age, sex and year of diagnosis. Lung cancer, non melanoma skin cancer and multiple primary cancers were excluded from the control group. Smoking information (smoking status, average number of cigarettes smoked per day, total number of years smoked, and similar information for pipe and cigars) was obtained from the medical charts of patients at the Windsor Regional Cancer Centre. Address at residence and residential duration was obtained from the Windsor City Directories as follows: using the patient's name and address at diagnosis from the medical charts, addresses were then verified backward in the Windsor City Directories every five years until the patient's name could no longer be found; addresses were then verified annually to obtain the last known address of residence in the City of Windsor. For each subject, the total number of years lived at a given address of residence was derived from this information.

\subsection{Exposure levels}

Annual levels of $\mathrm{NO}_{2}$ and $\mathrm{SO}_{2}$ for the year 2004 were estimated by the Land Use Regression model for each postal code in the City of Windsor based on results from 54 monitors set-up under the BAQS (Wheeler [9]). Land Use Regression (LUR) uses measured air pollution concentrations from networks as the response variable, and land use types within circular areas, called buffers, as predictors of changes of the measured concentrations ((Jerrett [10]). The variables used to create the LUR included: land-use groups (such as open space, industrial, commercial and residential land use); road network groups (such as length of local and major roads, length of primary highways and expressways), population and dwelling groups, and Detroit and Windsor industrial point sources variables (Wheeler [9]). The 1986-2003 pollution data was limited to observations from the National Air Pollution Surveillance (NAPS) Network [11], established as a joint Federal and Provincial program in 1969 to provide accurate and long-term air quality data of a uniform standard throughout Canada. NAPS sites only had up to 5 monitors during the years of our study compared to 54 monitors used in the BAQS study. To obtain annual estimates for each location for the entire 
study period (1986-2004) information from both the BAQS LUR model and NAPS sites were used. Firstly, the LUR estimates were adjusted using the average air pollution levels from the 2004 BAQS monitors and the average of the 2004 NAPS monitors (adjusted estimates $=$ LUR estimates / BAQS average $\times$ 2004 NAPS average). Secondly, the average yearly values for the remaining years (1986-2003) were adjusted to the 2004 adjusted values (adjusted yearly estimates $=$ adjusted estimates $/ 2004$ NAPS average $\times$ NAPS yearly average).

\subsection{Cases and controls exposure profile}

From 1986 to the year of diagnosis, for each incident case and control and for each air pollutant $\left(\mathrm{NO}_{2}\right.$ and $\left.\mathrm{SO}_{2}\right)$ an exposure profile was created consisting of the annual estimates, as described above, at each of the subject's residence (the centroid of the address postal was used as proxy for the residence location). For each year for which address information was unavailable for a subject we imputed missing values using the observed control mean imputation method (Weinberg et al. [12]). To investigate possible associations between long-term exposure to ambient pollution and lung cancer risk the average annual pollutant levels during the study period (i.e. from year 1986 to the year of diagnosis) was used for each pollutant as surrogate measure of exposure (individual pollution score).

\subsection{Statistical analyses}

Data analysis was conducted using conditional likelihood regression for matched or stratified data (Breslow and Day [13]). All regression models for the evaluation of air pollution effects included four covariates: sex, age at diagnosis, number of cigarettes smoked per day, and duration of cigarette smoking. These factors were included as stratification variables in the regression model. The pollution scores (as described above) were used as proxies for pollution levels. Analyses were done by categorizing exposures to various pollutants into discrete categories. Odds ratios and associated confidence intervals were calculated using matched conditional logistic regression (Breslow and Day [13]). The models were fitted using the PECAN module in the Epicure software package, which calculates parameter estimates using conditional analytic methodology (Preston et al. [14]).

\section{Results}

This report includes all subjects diagnosed from January 1st 2000 to December 31st 2004 inclusive, whose medical charts were accessible in electronic format. The 1422 subjects (711 lung cancer cases and 711 controls) represent 28 percent of the entire study population. The characteristics of cases and controls are shown in Table 1. Smoking information (ever/never) was obtained in over $80 \%$ of cases and controls, with data on number of cigarettes smoked per day and 
Table 1: $\quad$ Characteristics of cases and controls.

\begin{tabular}{|c|c|c|c|c|c|c|c|c|}
\hline & \multicolumn{4}{|c|}{ Males } & \multicolumn{4}{|c|}{ Females } \\
\hline & \multicolumn{2}{|c|}{ Cases } & \multicolumn{2}{|c|}{ Controls } & \multicolumn{2}{|c|}{ Cases } & \multicolumn{2}{|c|}{ Controls } \\
\hline & \# & $\%$ & & $\%$ & \# & $\%$ & \# & $\%$ \\
\hline Age (years) & & & & & & & & \\
\hline$<60$ & 74 & 19.0 & & 19.0 & 88 & 27.3 & 88 & 27.3 \\
\hline $60-69$ & 115 & 29.6 & 115 & 29.6 & 94 & 29.2 & 94 & 29.2 \\
\hline$\geq 70$ & 200 & 51.4 & 200 & 51.4 & 140 & 43.5 & 140 & 43.5 \\
\hline Average & \multicolumn{2}{|c|}{68.4} & \multicolumn{2}{|c|}{68.4} & \multicolumn{2}{|c|}{66.1} & \multicolumn{2}{|c|}{66.1} \\
\hline Smoking Status & & & & & & & & \\
\hline Never smoker & 12 & 3.1 & 93 & 23.9 & 23 & 7.1 & 169 & 52.5 \\
\hline Ever smoker & 310 & 79.7 & 257 & 66.1 & 253 & 78.6 & 128 & 39.8 \\
\hline Unknown & 67 & 17.2 & 39 & 10.0 & 46 & 14.3 & 25 & 7.8 \\
\hline \multicolumn{9}{|l|}{ Cigarettes per day } \\
\hline Unknown & 112 & 28.8 & 126 & 32.4 & 81 & 25.2 & 65 & 20.2 \\
\hline 0 & 14 & 3.6 & 103 & 26.5 & 23 & 7.1 & 169 & 52.5 \\
\hline $1-9$ & 8 & 2.1 & 13 & 3.3 & 11 & 3.4 & 14 & 4.3 \\
\hline $10-19$ & 24 & 6.2 & 25 & 6.4 & 44 & 13.7 & 19 & 5.9 \\
\hline $20-29$ & 132 & 33.9 & 81 & 20.8 & 121 & 37.6 & 45 & 14.0 \\
\hline$\geq 30$ & & 25.4 & 41 & 10.5 & 42 & 13.0 & 10 & 3.1 \\
\hline Average & \multicolumn{2}{|c|}{25.9} & \multicolumn{2}{|c|}{14.0} & \multicolumn{2}{|c|}{18.7} & \multicolumn{2}{|c|}{6.3} \\
\hline \multicolumn{9}{|l|}{$\begin{array}{c}\text { Duration of } \\
\text { smoking (years) }\end{array}$} \\
\hline Unknown & 145 & 37.3 & 134 & 34.4 & 100 & 31.1 & 65 & 20.2 \\
\hline 0 & 16 & 4.1 & 103 & 26.5 & 23 & 7.1 & 169 & 52.5 \\
\hline $1-24$ & 21 & 5.4 & 55 & 14.1 & 29 & 9.0 & 29 & 9.0 \\
\hline $25-34$ & 36 & 9.3 & 32 & 8.2 & 38 & 11.8 & 23 & 7.1 \\
\hline $35-44$ & & 18.0 & 25 & 6.4 & 55 & 17.1 & 17 & 5.3 \\
\hline$\geq 45$ & 101 & 26.0 & 40 & 10.3 & 77 & 23.9 & 19 & 5.9 \\
\hline Average & \multicolumn{2}{|c|}{39.1} & \multicolumn{2}{|c|}{18.8} & \multicolumn{2}{|c|}{35.4} & \multicolumn{2}{|c|}{10.7} \\
\hline \multicolumn{9}{|l|}{$\begin{array}{c}\text { Residence } \\
\text { duration (years) }\end{array}$} \\
\hline$<10$ & 50 & 12.9 & 33 & 8.5 & 45 & 14.0 & 26 & 8.1 \\
\hline $10-19$ & 82 & 21.1 & 66 & 17.0 & 77 & 23.9 & 75 & 23.3 \\
\hline$\geq 20$ & 257 & 66.1 & 290 & 74.6 & 200 & 62.1 & 221 & 68.6 \\
\hline Average & 27 & & & .6 & & .0 & & \\
\hline Total number & \multicolumn{4}{|c|}{389} & \multicolumn{4}{|c|}{322} \\
\hline
\end{tabular}


years of smoking being known for about two thirds of the subjects. The average number of cigarette smoked per day and the average years of smoking of lung cancer cases was about twice that of male controls, and three times that of female controls. The majority of cases and controls lived over 20 years in the City of Windsor. No significant relationships were observed between exposure to $\mathrm{SO}_{2}$ and lung cancer (data not shown). Results for $\mathrm{NO}_{2}$ are presented in Table 2.

Significant associations between $\mathrm{NO}_{2}$ levels and lung cancer were noted for males only (Table 2a). Significance persisted after controlling for residential duration, smoking duration and number of cigarette smoked per day, using the categories described in Table 1.

Table 2a: $\quad$ Lung cancer odds ratios (ORs) with 95\% confidence intervals (CI) by mean $\mathrm{NO}_{2}$ levels for male subjects with full smoking information.

\begin{tabular}{|c|c|c|c|c|c|}
\hline $\begin{array}{c}\mathrm{NO}_{2} \text { level } \\
\left(\mathrm{ug} / \mathrm{m}^{3}\right)\end{array}$ & $\begin{array}{l}\text { Cases } \\
(\mathrm{n}=231)\end{array}$ & $\begin{array}{l}\text { Controls } \\
(\mathrm{n}=243)\end{array}$ & & $\begin{array}{l}\text { Odds ratio } \\
(95 \% \mathrm{CI})\end{array}$ & $\begin{array}{c}\mathrm{p}- \\
\text { value }\end{array}$ \\
\hline \multicolumn{6}{|c|}{ Stratification by Age } \\
\hline$<21.0$ & $30(13 \%)$ & $58(24 \%)$ & 1.00 & & \\
\hline $21.0-23.5$ & $84(36 \%)$ & $81 \quad(33 \%)$ & 1.92 & $(1.1$ & 0.02 \\
\hline $23.5-26.0$ & $63(27 \%)$ & $64(26 \%)$ & 1.83 & $(1.0$ & 0.03 \\
\hline $26.0-28.5$ & $45(19 \%)$ & $35(14 \%)$ & 2.37 & $(1$. & 0.01 \\
\hline$>28.5$ & $9 \quad(4 \%)$ & $5 \quad(2 \%)$ & 3.36 & $(1.0$ & 0.04 \\
\hline \multicolumn{6}{|c|}{ Stratification by Age and Residence Duration } \\
\hline$<21.0$ & $30(13 \%)$ & $58(24 \%)$ & 1.00 & & \\
\hline $21.0-23.5$ & $84(36 \%)$ & $81 \quad(33 \%)$ & 2.05 & $(1.1$ & 0.01 \\
\hline 23.5 & $63(27 \%)$ & $64(26 \%)$ & 1.90 & $(1$. & 0.03 \\
\hline $26.0-28.5$ & $45(19 \%)$ & $35(14 \%)$ & 2.43 & $(1$. & 0.01 \\
\hline$>28.5$ & $9 \quad(4 \%)$ & $5 \quad(2 \%)$ & 3.41 & $1.05-11.1)$ & 0.04 \\
\hline \multicolumn{6}{|c|}{$\begin{array}{c}\text { Stratification by Age, Residence Duration, Duration of } \\
\text { smoking and Cigarettes per day }\end{array}$} \\
\hline$<21.0$ & $30(13 \%)$ & $58(24 \%)$ & 1.00 & & \\
\hline $21.0-23.5$ & $84(36 \%)$ & $81 \quad(33 \%)$ & 3.04 & (1.38- & 0.01 \\
\hline $23.5-26.0$ & $63(27 \%)$ & $64(26 \%)$ & 1.47 & $(0.67-3.21)$ & 0.34 \\
\hline $26.0-28.5$ & $45(19 \%)$ & $35(14 \%)$ & 2.80 & $(1.18-6.61)$ & 0.02 \\
\hline$>28.5$ & $9 \quad(4 \%)$ & $5 \quad(2 \%)$ & 5.49 & $(1.04-29.0)$ & 0.05 \\
\hline
\end{tabular}


Table 2b: $\quad$ Lung cancer odds ratios (ORs) with 95\% confidence intervals (CI) by mean $\mathrm{NO}_{2}$ levels for female subjects with full smoking information.

\begin{tabular}{|c|c|c|c|c|}
\hline $\begin{array}{l}\mathrm{NO}_{2} \text { level } \\
\left(\mathrm{ug} / \mathrm{m}^{3}\right)\end{array}$ & $\begin{array}{c}\text { Cases } \\
(\mathrm{n}=209)\end{array}$ & $\begin{array}{l}\text { Controls } \\
(\mathrm{n}=244)\end{array}$ & $\begin{array}{l}\text { Odds ratio } \\
(95 \% \mathrm{CI})\end{array}$ & $\begin{array}{c}\mathrm{p}- \\
\text { value }\end{array}$ \\
\hline \multicolumn{5}{|c|}{ Stratification by Age } \\
\hline$<21.0$ & $30(14 \%)$ & $41(17 \%)$ & 1.00 & \\
\hline $21.0-23.5$ & $89(43 \%)$ & $98(40 \%)$ & $1.23(0.71-2.15)$ & 0.46 \\
\hline $23.5-26.0$ & $49(23 \%)$ & $64(26 \%)$ & $1.01 \quad(0.55-1.85)$ & $>0.5$ \\
\hline $26.0-28.5$ & $32(15 \%)$ & $29(12 \%)$ & $1.53(0.77-3.06)$ & 0.23 \\
\hline$>28.5$ & $9 \quad(4 \%)$ & $12(5 \%)$ & $1.07 \quad(0.40-2.88)$ & $>0.5$ \\
\hline \multicolumn{5}{|c|}{ Stratification by Age and Residence Duration } \\
\hline$<21.0$ & $30(14 \%)$ & $41(17 \%)$ & 1.00 & \\
\hline $21.0-23.5$ & $89(43 \%)$ & $98(40 \%)$ & $1.26 \quad(0.72-2.21)$ & 0.42 \\
\hline $23.5-26.0$ & $49(23 \%)$ & $64(26 \%)$ & $1.00 \quad(0.54-1.83)$ & $>0.5$ \\
\hline $26.0-28.5$ & $32(15 \%)$ & $29(12 \%)$ & $1.59 \quad(0.79-3.17)$ & 0.19 \\
\hline$>28.5$ & $9 \quad(4 \%)$ & $12 \quad(5 \%)$ & $1.06 \quad(0.39-2.86)$ & $>0.5$ \\
\hline \multicolumn{5}{|c|}{$\begin{array}{c}\text { Stratification by Age, Residence Duration, Duration of } \\
\text { smoking and Cigarettes per day }\end{array}$} \\
\hline$<21.0$ & $30(14 \%)$ & $41(17 \%)$ & 1.00 & \\
\hline $21.0-23.5$ & $89 \quad(43 \%)$ & $98(40 \%)$ & $2.14 \quad(0.91-5.03)$ & 0.08 \\
\hline $23.5-26.0$ & $49(23 \%)$ & $64(26 \%)$ & $1.42 \quad(0.56-3.58)$ & 0.46 \\
\hline $26.0-28.5$ & $32(15 \%)$ & $29(12 \%)$ & $1.54 \quad(0.59-4.02)$ & 0.38 \\
\hline$>28.5$ & $9 \quad(4 \%)$ & $12(5 \%)$ & $1.22 \quad(0.26-5.64)$ & $>0.5$ \\
\hline
\end{tabular}

\section{Discussion}

Reviews of lung cancer risk from air pollution exposures have reported associations with exposure to particulate and gases including $\mathrm{SO}_{2}$ and $\mathrm{NO}_{2}$ (Cohen and Pope [15], Katsouyanni and Pershagen [16]). Significant relationships with $\mathrm{SO}_{2}$ have been found by some authors (Dockery et al. [1], Beeson et al. [4] , Jedrychowski et al. [17]) but not all (Nyberg [5], Nafstad [6], Beelan [18] ), and this report. Similarly positive relationships with $\mathrm{NO}_{2}$ have been noted (Filleul et al. [19], Naess et al. [20]), but not in a study examining air pollution related to exposure to traffic (Beelen et al. [18]).

In this study, a significant association between lung cancer and long-term exposure to $\mathrm{NO}_{2}$ was clearly shown in males, but not in females. Although 
limited by the fact that a subset of the study population has been analysed at this time and thereby that caution must be exercised in interpreting the data, these results are nonetheless strengthened by the fact that a) the number of cases and controls are relatively large; b) cumulative exposure was assessed for each subject based on residential exposure estimates; c) odds ratios were adjusted for smoking intensity and duration, and for residential duration in the City of Windsor. Final conclusion will have to await analyses of the full study population.

\section{Disclaimer}

Parts of this research are based on data provided by Cancer Care Ontario. However, the analysis, conclusions, opinions and statements expressed are those of the authors and not necessarily those of Cancer Care Ontario.

\section{Acknowledgment}

The financial support from the Clean Air Regulation Act, Health Canada, is gratefully acknowledged.

\section{References}

[1] Dockery DW, Pope A, Xiping X, Spengler JD, Ware JH, Fay ME, Ferris BG, Speizer FE. An association between air pollution and mortality in six U.S. cities. N Engl J Med, 329, pp.1753-1759, 1993.

[2] Pope CA, Thun MJ, Namboodiri MM, Dockery DW, Evans JS, Speizer FE, Heath Jr CW. Particulate air pollution as a predictor of mortality in a prospective study of U.S. adults. Am J Respir Crit Care Med, 151, pp.669-674, 1995.

[3] Pope CA, Burnett RT, Thun MJ, Calle EE, Krewski D, Ito K, Thruston GD. Lung cancer, cardiopulmonary morality and long-term exposure to fine particulate air pollution. JAMA, 287, pp. 1132-1141, 2002.

[4] Beeson WL, Abbey DE, Knutsen SF. Long-term concentrations of ambient air pollutants and incident lung cancer in California adults: results from the AHSMOG study. Environ Health Perspect, 106, pp. 813-823, 1998.

[5] Nyberg F, Gustavsson P, Järup L, Bellander T, Berglind N, Jakobson R, Perhsagen G. Urband air pollution and lung cancer in Stockholm. Epidemiology, 11, pp. 487-495, 2000.

[6] Nafstad P, Håheim LL, Wisloff T, Gram F, Oftedal B, Holme I, Hjermann I, Leren P. Urban air pollution and mortality in a cohort of Norwegian men. Environ Health Perspect, 112, pp. 610-615, 2004.

[7] Nafstad P, Håheim LL, Oftedal B, Gram F, Holme I, Hjermann I, Leren P. Lung cancer and air pollution: 27 year follow up of 16209 Norwegian men. Thorax, 58, pp. 1071-1076, 2003. 
[8] Band PR, Zielinski JM, Jiang H, Liu L. Canada-US border air quality strategy (BAQS): preliminary results of mortality and cancer incidence in Windsor, Canada. In: "Air Pollution X1V" Longhurst JWS and Brebbia CA Eds. Wit Press, Southampton, Boston, pp 777-83, 2006.

[9] Wheeler AJ, Smith-Doiron M, Xu X, Gilbert NL, Brook JR. 2008. Intra-urban variability of air pollution in Windsor, Ontario--measurement and modeling for human exposure assessment. Environ Res 106, pp. 7-16, 2008.

[10] Jerrett M, Arain A, Kanaroglou P, Beckerman B, Potoglou D, Sahsuvaroglu T, Morrison J, Giovis C. A review and evaluation of intra-urban air pollution exposure models. $J$ Expo Anal Environ Epidemiol 15, pp. 185-204, 2005.

[11] National Air Pollution Surveillance (NAPS) Network Annual Dada Summary. Her Majesty the Queen in Right of Canada (Environment Canada). Online. http://www.etc-cte.ec.gc.ca/publications /napsreports_e.html.

[12] Weinberg, C. R., E. S. Moledor, D. M. Umbach, and D. P. Sandler. Imputation for exposure histories with gaps, under an excess relative risk model. Epidemiology 5, pp. 490-7, 1996.

[13] Breslow NE, Day NE. Statistical methods in cancer research. Volume 1. The design and analysis of case-control studies. International Agency for Research on Cancer. IARC Scientific Publication no. 32, Lyon, France, 1986

[14] Preston, D. L., Lubin, J. H., Pierce, D. A., and McConney, M. Epicure User's Guide. Seattle, Washington: Hirosoft International Corporation, 2000.

[15] Cohen AJ, Pope CA III. Lung cancer and air pollution. Environ Health Perspect 103 (Suppl 8), pp. 219-224, 1995.

[16] Katsouyanni K, Pershagen G. Ambient air pollution exposure and cancer. Cancer Causes Control 8, pp. 284-191, 1997.

[17] Jedrychowski W, Becher H, Wahrendorf J, Basa-Cierpialek Z. A case-control study of lung cancer with special reference to the effect of air pollution in Poland. J Epidemiol Community Health 44, pp.114-120, 1990.

[18] Beelen R, Hoek G, van den Brandt PA, Goldbolm A, Fischer P, Schouten $\mathrm{LJ}$, Armstrong $\mathrm{b}$, Brunekreef B. Long-term exposure to traffic-related air pollution and lung cancer risk. Epidemiology, 19, pp. 702-710, 2008.

[19] Filleul L, Rondeau V, Vandentorren S, Le Moual N, Cantagrel A, Annesi-Maesano I, Charpin D, Declercq C, Neukirch F, Paris C, Vervloet D, Brochard P, Tessier J-F, Kauffmann F, Baldi I. Twenty five year mortality and air pollution: results from the French PAARC survey. Occup Environ Med, 62, pp. 453-460, 2005.

[20] Naess Ø, Nafstad P, Aamodt G, Claussen B, Rosland P. Relation between concentration of air pollution and cause-specific mortality: four-year exposures to nitrogen dioxide and particulate matter pollutants in 470 neighborhoods in Oslo, Norway. Am J Epidemiol, 165, 435-443, 2007. 